\title{
OPPORTUNITIES OF AIRBORNE LASER BATHYMETRY FOR THE MONITORING OF THE SEA BED ON THE BALTIC SEA COAST
}

\author{
Joachim Niemeyer, ${ }^{* a}$ and Uwe Soergel ${ }^{b}$ \\ ${ }^{a}$ Institute of Photogrammetry and GeoInformation, Leibniz Universität Hannover, Germany \\ ${ }^{b}$ Institute of Geodesy, Chair of Remote Sensing and Image Analysis, TU Darmstadt, Germany \\ (niemeyer, soergel)@ipi.uni-hannover.de
}

Commission III/2

KEY WORDS: Laser Bathymetry, Coastal, 3D Point Cloud, LiDAR, Monitoring

\begin{abstract}
:
Traditional ship-based bathymetric surveys based on echo sounding are expensive and time consuming. This paper presents a project with the aim of identifying the opportunities of airborne laser bathymetry for the monitoring of the sea bed at the German Baltic Sea coast. Such devices operate with laser signal in the green part of the visible spectrum which is capable to penetrate the water. The depth is determined from the two-way runtime between the water surface and reflections from the ground underneath. Several flight campaigns in representative test areas will be carried out in order to analyze the reachable depths, the accuracies of the acquired points, and the detection of obstacles depending on different water conditions (e.g. turbidity). We discuss some preliminary results of a pilot project and the first campaign of a study area close to the island of Poel, Germany.
\end{abstract}

\section{INTRODUCTION}

The periodic monitoring of the sea bed is one of the most important tasks of the hydrographic authorities. The corresponding measurements of the underwater topography (bathymetry) and detection of obstacles, which guarantee the safe navigation of ships, are currently carried out by ship-based echo sounding, but this method is very expensive and time consuming. In addition, many operators are needed and it is a material-intensive technique. Due to international agreements and a steadily growing maritime traffic relying on high precision navigation systems the demand for monitoring campaigns has increased.

Particularly challenging are the shallow water regions between depth of $0 \mathrm{~m}$ and 1-2 m. Due to the draft this areas are often not accessible for vessels. Thus, data of these regions are difficult to obtain and often not very accurate, although they are needed for many applications such as a reliable determination of the coast line, coastal protection and coastal zone management.

In recent years the promising technique of airborne laser bathymetry (ALB) became more and more important thanks to improved hardware and better processing software. Such devices use green laser which can penetrate the water column. The depth is determined from the two-way runtime between the water surface and reflections from the solid ground underneath. Especially the pulse repetition rate and thus the point density have been significantly increased for state-of-the-art sensors. Good results under optimal conditions were observed (Irish and Lillycrop, 1999; Steinbacher et al., 2012). However, there are many limiting factors, in particular water turbidity. Some other issues are wind, the sea state, reflectance of the sea bed, and much more.

This paper puts emphasis on the goals of the project 'Investigation on the use of airborne laser bathymetry in hydrographic surveying', which is a cooperation of BSH (Federal Maritime and Hydrographic Agency of Germany) and IPI (Institute of Photogrammetry and GeoInformation, Leibniz Universität Hannover). It studies the opportunities of airborne laser bathymetry for the

${ }^{*}$ Corresponding author. monitoring of the sea bed in the Baltic Sea in comparison to traditional ship-based echo sounding. Several flight campaigns in representative test areas will be carried out in order to analyze the reachable depths, the accuracies of the acquired points, and the detection of obstacles depending on different water conditions (e.g. turbidity). In this investigation, we report preliminary results of the first campaign that took place in autumn of 2013.

\section{LASER BATHYMETRY}

Conventional bathymetry of water bodies is performed by echo sounding systems mounted on vessels. However, especially in shallow water (for example close to the coast) these ships cannot access some areas due to the draft. Thus, these areas are challenging for monitoring tasks. A relatively new method to obtain 3D information of near-shore shallow water regions is ALB. Mounted on an aircraft, a three dimensional description of the ground is obtained by laserscanning. In contrast to topographic scanners operating with near infrared laser, bathymetric sensors make use of green laser of $532 \mathrm{~nm}$ wavelength. These pulses are able to penetrate the water column and thus may reach the sea bed. The measuring depth is limited due to attenuation of the laser energy by absorption, scattering, and refraction effects while the laser pulse is traveling through the water column. Most sensors work with a combination of a near infrared and a green laser. In this case the infrared one is reflected from the water surface, whereas the green laser measures the ground. The difference of both levels corresponds to the water depth.

The first systems were introduced in the 1960th for military tasks such as the detection of submarines. Hickman and Hogg (1969) proposed to use an airborne laser for bathymetric surveying. In the next decades several prototypes of ALB sensors were developed, for example from NASA and the U.S. Navy. The Royal Australian Navy constructed the first operational system called LADS in 1986 (Lillycrop et al., 2002). As a strong green laser pulse is necessary in order to reach deeper areas in the ocean, the pulse repetition rate of the sensor was limited considerably. This leads to low point densities on the sea bed. Guenther et al. (2000) reported basic technical requirements for laser bathymetry 
and sensors are summarized by Mallet and Bretar (2009). Some systems of the newest generation, such as the Riegl VQ-820-G sensor (Riegl, 2013; Steinbacher et al., 2012) or Chiroptera (Airborne Hydrography AB, 2013), are especially designed for higher point densities in shallow water regions of about one Secchi depth (the maximum depth of which the human eye can detect a specific disk in the water) by increasing the pulse repetition rate. However, they are not suitable for deeper water because the energy of a pulse is too low for a longer travel through the water column. Thus, the sensors can be divided into two groups. In some cases a combined survey of bathymetric and topographic (on-shore) survey is possible, which may decrease the relative costs and lead to more homogeneous data sets.

Many of the published civil applications with laser bathymetry have taken place in test studies with clear water. Promising results were obtained here and measurements of up to $60 \mathrm{~m}$ have been reported (Irish and Lillycrop, 1999). In Costa et al. (2009) it was shown that laser bathymetry was $6.6 \%$ cheaper and took 40 hour less processing time with a drawback of lower spatial resolution compared to multi-beam sonar for a coral reef mapping project with water deeper than $50 \mathrm{~m}$. In the case of Germany the BSH is responsible for bathymetric surveys of the North Sea and the Baltic Sea. However, there are strong tidal effects at the North Sea coast leading to a turbidity of the water due to the whirled sediments. In contrast the water of the Baltic Sea coast is much clearer, although it is still not optimal for laser bathymetry. This is the reason why the work of the presented project focuses on the Baltic Sea coast.

\section{PILOT STUDY}

In June 2008 a first pilot study was conducted by BSH. The study area was an approx. $14 \mathrm{~km}^{2}$ large region located close to the island of Poel in the German Baltic sea coast. The company Blom acquired data with a Hawkeye II sensor, carried on a Rockwell Aero Commander 690 aircraft. Flying height was $400 \mathrm{~m}$. During acquisition it was partly windy with a little surge of waves. The delivery comprised $\mathrm{x}, \mathrm{y}, \mathrm{z}$ coordinates of the echoes and we do not have access to the full waveform data.

The Hawkeye II sensor was designed to reach up to 3 times Secchi depth. This is made possible by powerful pulses of a length of $5 \mathrm{~ns}$, on the downside this comes along with a relatively low pulse rate of $4000 \mathrm{~Hz}$ only resulting in lower point densities. However, due to this configuration such device is suitable for the acquisition of comparatively deep or turbid water. Figure 1 shows the actual penetration depth at the coast of Poel. The maximum was about $14.5 \mathrm{~m}$. Nevertheless, the point density for areas deeper than $10 \mathrm{~m}$ is quite low (Fig. 2).

In addition to the surveying flight with laser bathymetry, shipborne single-beam and multi-beam echo sounding were carried out in parts of this area in order to obtain some reference measurements. An evaluation has shown comparable results of the laser point cloud and the conventional bathymetry with only small differences.

The bottom line of the pilot project was that laser bathymetry is worthwhile for BSH to be investigated in more detail. Moreover, the rapid sensor development is encouraging. However, due to water turbidity ALB would be pointless in the North Sea, thus the further investigations focus on the Baltic Sea.

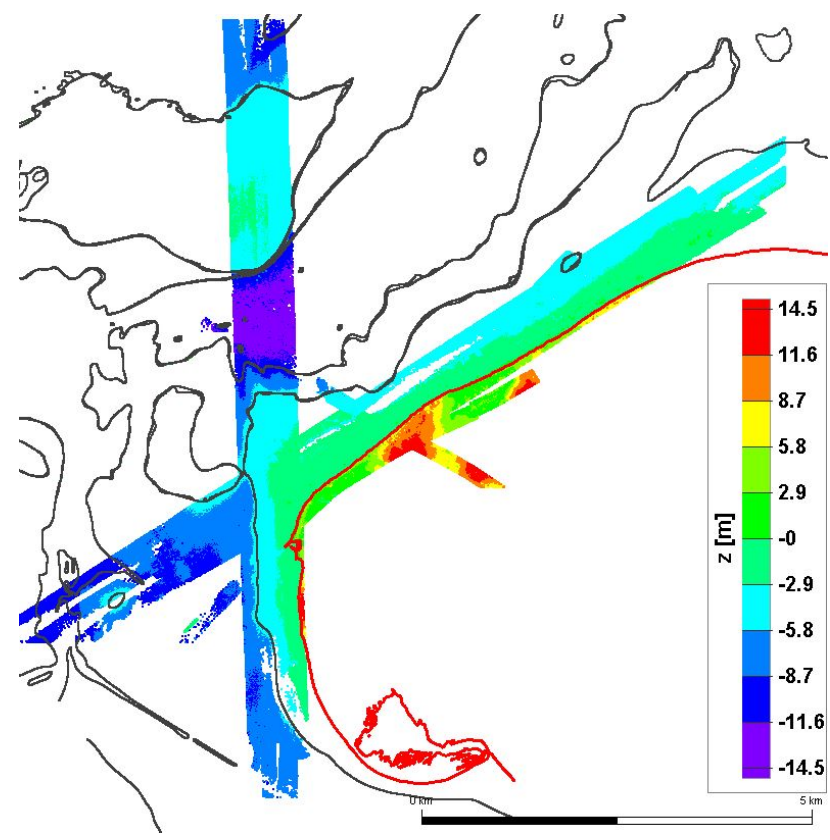

Figure 1: Pilot study - penetration depth of Hawkeye II.

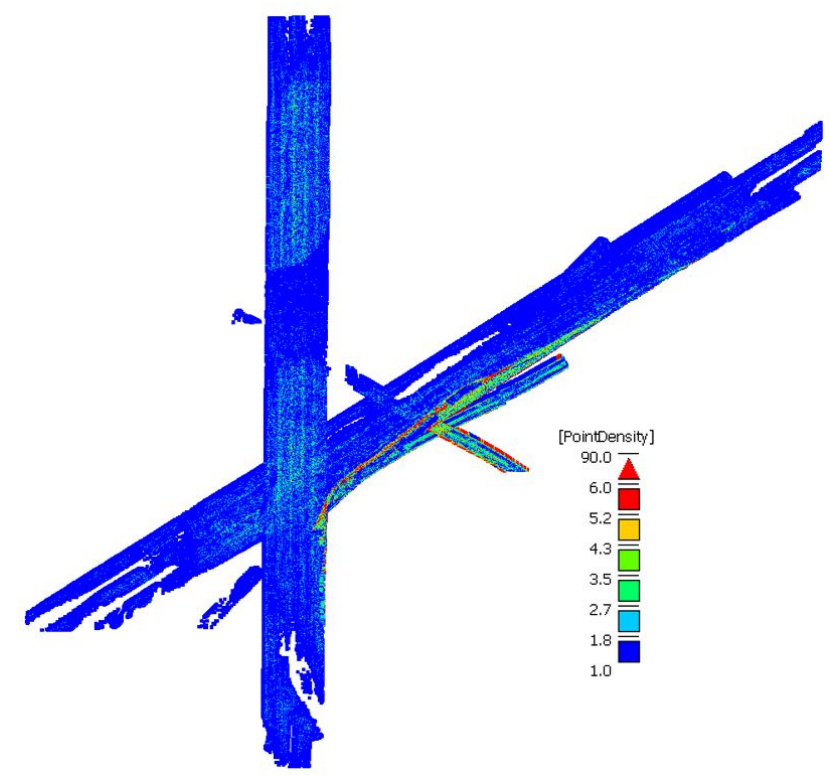

Figure 2: Pilot study - point density of Hawkeye II.

\section{PROJECT}

\subsection{Goals of the Project}

After the encouraging pilot study, the BSH decided in the mid of 2011 to launch a 3 year project from 2012 to 2014 in order to evaluate the potential of laser bathymetry in the area of the German Baltic Sea coast in more detail. A focus is on the quality of the data as well as on the economic aspects compared to conventional echo sounding systems. The most important question which should be answered at the end of the project is: Can laser bathymetry be used alternatively at least for a subset of BSH's tasks? If so, is this economic for operational application? Therefore, three surveying flights (one in each year) are planned. Additionally to the laserscannings, reference measurements for instance with conventional ship-borne bathymetry will be con- 
ducted. In the context of the project a collaboration with the IPI as a scientific partner was started. Both partners, BSH and IPI, will validate the geometric accuracy of the laser data. Furthermore, IPI will investigate the full waveform data in order to find out whether obstacles such as stones can be detected in the data. Of special interest are also shallow water areas and the transition zone to shore. Taken as a whole all environmental influences such as water turbidity, weather, strength of the waves and so on should be determined to figure out the limitations of the technique. That is why heterogeneous test areas close to the island of Poel in the Baltic Sea were chosen.

Considering the quality of the data, laser bathymetry must meet the constraints of the IHO Standards for Hydrographic Surveys (S-44) (International Hydrographic Organization, 2008), Order 1a specifications to partly substitute ship-based bathymetry. To live up to this standard, full sea floor coverage is required during surveying. Moreover, it must be possible to detect cubic obstacles of size of larger than $2 \mathrm{~m}$ in up to $40 \mathrm{~m}$ depth. The maximum allowable total horizontal uncertainty (THU) is defined by

$$
T H U_{\max }=5 m+5 \% \text { depth }
$$

whereas the total vertical uncertainty is computed by

$$
T V U_{\max }= \pm \sqrt{(0.5 m)^{2}+(0.013 \cdot \operatorname{depth})^{2}}
$$

For both parameters a $95 \%$ confidence level must be fulfilled.

Based on the experience of the latest campaign, the call of tender for the next surveying is designed and adapted. This also enables to react more quickly on ongoing developments of sensors. Beside BSH and IPI also the federal states and other authorities are involved in the project.

\subsection{First Campaign}

4.2.1 Study Area For the first campaign of data acquisition four test sites situated near the island of Poel, Germany were chosen. An overview illustrating their extent and water depth is given in Fig. 3 and 4. Area 1 reaches from west to east and is the largest test site with $136 \mathrm{~km}^{2}$. It touches the coast, but mainly consists of water regions. The water depth reaches up to approx. $25 \mathrm{~m}$. This area also includes a shallow water region of a depth with 3-4 m called Hannibal and some larger stones, which may be an obstacle for ships. Area 2 is also orientated in west-east direction, and the $84 \mathrm{~km}^{2}$ are seamlessly situated in the north of Area 1. It comprises water of the depth of 10 to $15 \mathrm{~m}$ in the main, but also covers an island in the east. The other two areas reach from south-west to north-east. Area 3 has a size of $104 \mathrm{~km}^{2}$ and is located in water regions completely. The maximum depth is up to $21 \mathrm{~m}$ on the one hand, but it also comprises the shallow water region Hannibal on the other hand. In contrast, Area 4 covers the coast of Poel. In the $21 \mathrm{~km}^{2}$ region, some parts are onshore. A large variation of the water depth can be observed here; it reaches from very shallow water at the beach to $15 \mathrm{~m}$. Attention hast to be paid while using a laser bathymetry sensor in this area due to eye safety reasons, because there are some people living in villages next to the coast. Orthophotos were provided for this area additionally, but the date of acquisition was one month before the laser survey.

4.2.2 Framework conditions The data acquisition was performed by Milan Geoservice $\mathrm{GmbH}$ in the time from $31^{\text {st }} \mathrm{Oc}$ tober to $14^{\text {th }}$ November 2012 with a Cessna C207 and a Piper Seneca PA34 carrier. The sensor was a Riegl VQ-820-G device,

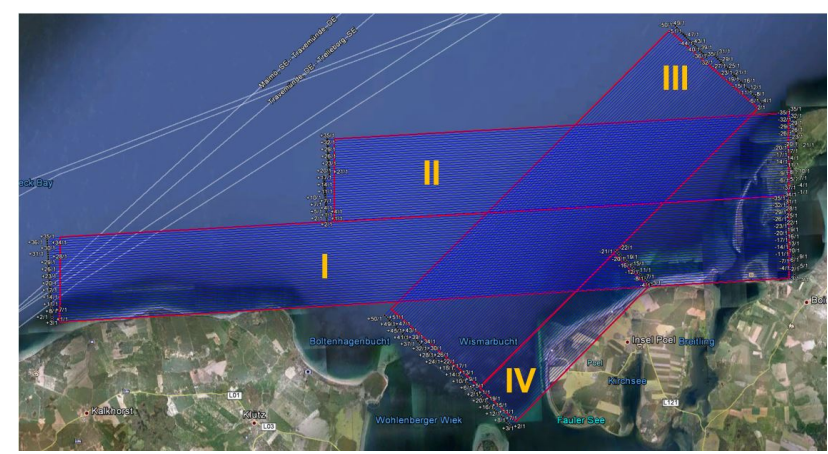

Figure 3: Overview of the four test areas situated close to the island of Poel in the German Baltic Sea.

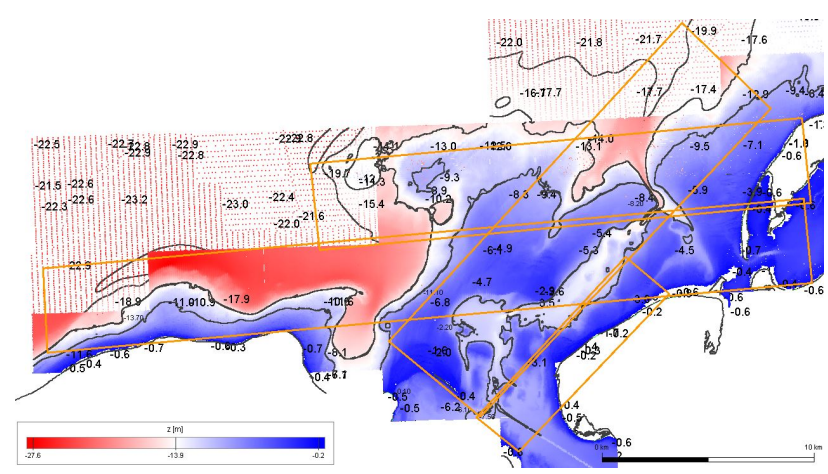

Figure 4: Overview of the water depth in the test areas.

which works with a green laser. For this survey the pulse repetition rate was set to $120 \mathrm{kHz}$. The typical measurement range is 1 Secchi depth (Riegl, 2013). A scan pattern of an elliptical arc segment aimed ahead of the aircraft helps to obtain a nearly constant incident angle. This is helpful for the correction of refraction occurring at the water surface.

In order to assess the quality of the results and its dependence on different influences, the data was acquired with several flying heights above ground. Area 1 and 2 are flown with 300, 500, and $700 \mathrm{~m}$, respectively. This enables for instance a comparison of the point densities in each configuration. For Area 3 only the altitude of $500 \mathrm{~m}$ was used. In the case of Area 4 a restriction had to be considered: the area comprises some onshore parts with buildings. Due to eye safety reasons the minimal allowed flying height for this sensor is $600 \mathrm{~m}$, which corresponds to the altitude which was used. Taking the multiple flying heights into account, an area of $785 \mathrm{~km}^{2}$ was surveyed. The number of flight strips is summarized in Tab. 1 .

There were several barriers in the time of flight. For six days there were low clouds and it rained, thus no acquisition was possible. Moreover, there was a navy exercise close by the study area for four days, which also restricted the acquisition. Another difficulty concerning the size of Area 1 and 2 appeared due to migrating birds which stayed at an island for bird protection in the east of the areas. Here the authorities prohibited the data acquisition with the lowest altitude of $300 \mathrm{~m}$. Thus, both areas are a

\begin{tabular}{|c|c|c|c|}
\hline Area & Size $\left[\mathrm{km}^{2}\right]$ & Altitude $[\mathrm{m}]$ & Strips \\
\hline I & 136 & $300,500,700$ & 71 \\
II & 84 & $300,500,700$ & 70 \\
III & 84 & 500 & 34 \\
IV & 21 & 600 & 12 \\
\hline
\end{tabular}

Table 1: Summary of the flights. 


\begin{tabular}{|c|c|c|c|}
\hline Area 1 & $300 \mathrm{~m} *$ & $500 \mathrm{~m}$ & $700 \mathrm{~m}$ \\
\hline \# of points & $888,141,103$ & $113,916,063$ & $13,256,704$ \\
Noise & $0.45 \%$ & $0.32 \%$ & $0.65 \%$ \\
Water surface & $45.09 \%$ & $18.44 \%$ & $1.28 \%$ \\
Sea bed & $33.46 \%$ & $56.17 \%$ & $38.18 \%$ \\
Vegetation & $5.2 * e^{-6} \%$ & $0.04 \%$ & - \\
Onshore & $21.00 \%$ & $25.04 \%$ & $59.89 \%$ \\
\hline
\end{tabular}

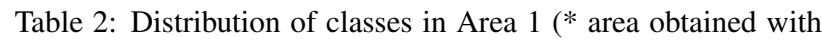
$300 \mathrm{~m}$ altitude is smaller).

\begin{tabular}{|c|c|c|c|}
\hline Area 2 & $300 \mathrm{~m} *$ & $500 \mathrm{~m}$ & $700 \mathrm{~m}$ \\
\hline \# of points & $134,770,086$ & $67,942,332$ & $25,124,149$ \\
Noise & $0.10 \%$ & $0.30 \%$ & $0.33 \%$ \\
Water surface & $98.98 \%$ & $28.19 \%$ & $2.59 \%$ \\
Sea bed & $0.92 \%$ & $11.00 \%$ & $24.56 \%$ \\
Vegetation & - & - & - \\
Onshore & - & $60.52 \%$ & $72.51 \%$ \\
\hline
\end{tabular}

Table 3: Distribution of classes in Area 2 (* area obtained with $300 \mathrm{~m}$ altitude is smaller).

bit smaller in this configuration, because the highlighted areas in Fig. 5 were not accessible.

4.2.3 Statistics concerning the study areas As stipulated in the contract, the delivery of the data comprises the point coordinates with the attributes concerning the echo return number, intensity values as well as a classification in one of the six object classes for each laser point:

$$
\begin{aligned}
& \text { - Onshore } \\
& \text { - Water surface } \\
& \text { - Sea bed } \\
& \text { - Water vegetation } \\
& \text { - Underwater obstacles } \\
& \text { - Noise }
\end{aligned}
$$

The processed point cloud was also corrected to account for the angle of refraction, when the laser beam penetrated the water body on the water surface. Moreover, the speed of light is reduced in water compared to the propagation in the air. This difference in velocity must also be corrected. In addition to the processed point cloud the original waveform information was delivered for further research, too. The statistics of the Tables 2-4 are based on the classification performed by Milan Geoservice.

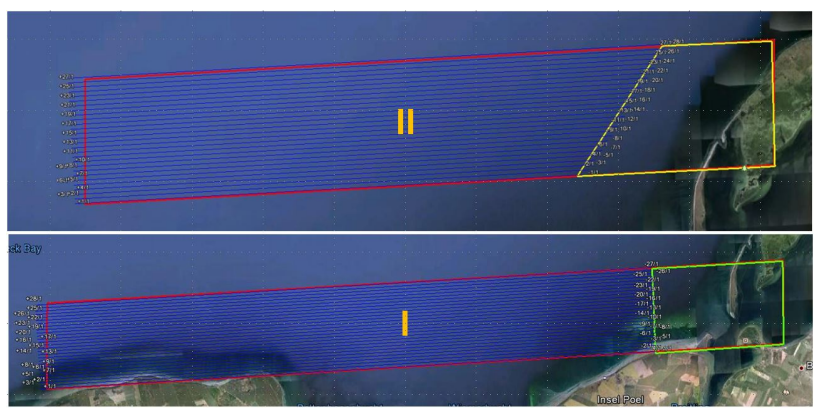

Figure 5: Lowest altitude ( $300 \mathrm{~m}$ ) for Area 1 and 2 is not possible in highlighted parts because of migrating birds.

\begin{tabular}{|c|c|c|}
\hline & Area 3, 500 $\mathrm{m}$ & Area 4, 600 m \\
\hline \# of points & $101,029,534$ & $57,120,657$ \\
Noise & $0.25 \%$ & $0.34 \%$ \\
Water surface & $78.22 \%$ & $8.35 \%$ \\
Sea bed & $21.43 \%$ & $20.97 \%$ \\
Vegetation & - & - \\
Onshore & $0.10 \%$ & $70.34 \%$ \\
\hline
\end{tabular}

Table 4: Distribution of classes in Area 3 and 4.

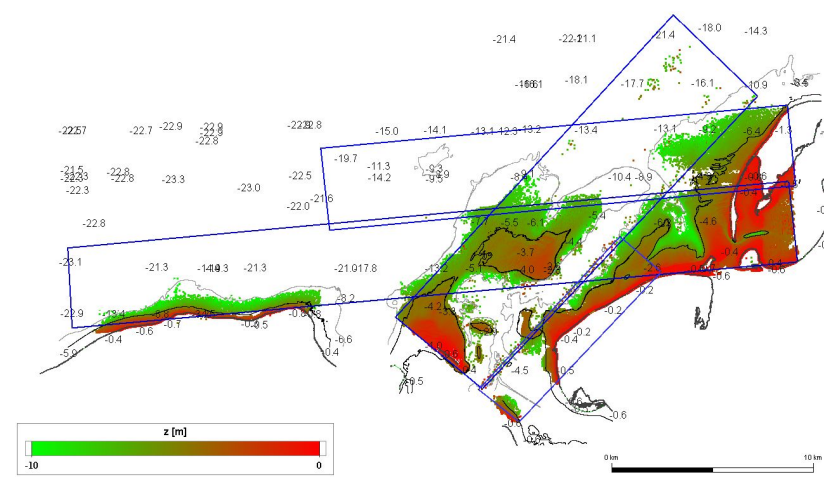

Figure 6: Sea bed points and test areas. Red is $0 \mathrm{~m}$ and green is $10 \mathrm{~m}$ depth. Additionally the coast line, the depth at 5 and at $10 \mathrm{~m}$ are displayed.

In fact only the altitudes of 500 and $700 \mathrm{~m}$ of Area 1 and 2 are comparable, respectively, because the area of the $300 \mathrm{~m}$ flying height is smaller as already mentioned. It can be seen that the lower altitude leads to an about 8 times bigger point cloud in case of Area 1. For Area 2 the factor is only about 2.7 times. A correlation of altitude and number of sea bed points is also not observable. It seems to strongly depend on the exterior environmental conditions. The number of points assigned to the classes underwater vegetation or obstacles is neglectable. An overview of all sea bed points obtained with 500 and $600 \mathrm{~m}$, respectively, can be found in Fig. 6 .

4.2.4 Preliminary evaluation of Area 4 In the next part a preliminary and exemplary analysis of Area 4 is performed. Unfortunately, it was not possible to evaluate the surveys in depth due to some some delays in data processing and calibration work flow. Analyzing solely the points classified as sea bed, a depth of about one Secchi depth, which was approximately $6 \mathrm{~m}$, can be observed as expected. Less than $1 \%$ of all sea bed points have a depth larger than $4 \mathrm{~m} .4 .3 \%$ of the points are measured at a height level from $-3 \mathrm{~m}$ to $-4 \mathrm{~m}$. The majority of the points is between 0 and $-1 \mathrm{~m}(>56 \%)$. Of course this distribution can be partly explained by the topography of the sea ground in this area. The values are visualized in Fig. 7-10.

The preliminary results also reveal that a high point density was achieved in the very shallow water areas (Fig. 10). Between 0 and $-1 \mathrm{~m}$ the point density is $6.3 \mathrm{pts} / \mathrm{m}^{2}$ in the mean. It decreases to $5.2 \mathrm{pts} / \mathrm{m}^{2}$ ( -1 to $\left.-2 \mathrm{~m}\right), 2.6 \mathrm{pts} / \mathrm{m}^{2}$ at -2 to $-3 \mathrm{~m}, 1.6 \mathrm{pts} / \mathrm{m}^{2}$ at a -3 to $-4 \mathrm{~m}$ level, and close to $1 \mathrm{pt} / \mathrm{m}^{2}$ for areas lower than $-4 \mathrm{~m}$. Accordingly to the number of points in the elevation levels, the standard deviation of the point densities also decreases. An evaluation of the data in future work will show, if the LiDAR point cloud meets the IHO S-44, Order 1a specifications.

\subsection{Second Campaign}

Meanwhile the tender process for the second campaign was successfully completed. The companies AHAB and Topscan secured the order to acquire data in September 2013. The focus of this 


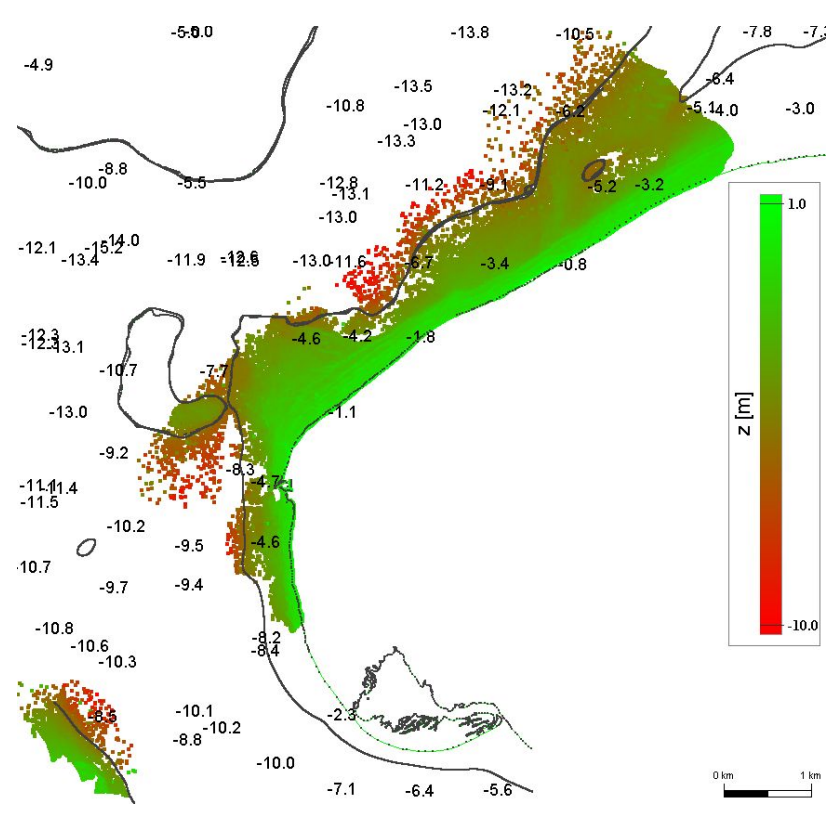

Figure 7: Depth of sea bed points (Area 4) with $5 \mathrm{~m}$ isobath.

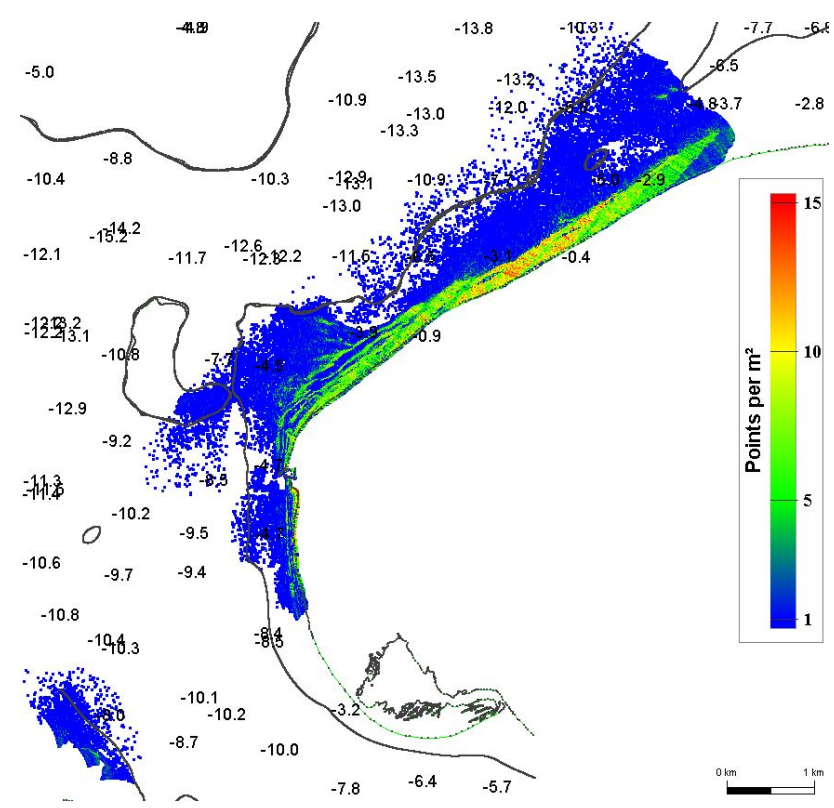

Figure 8: Area 4 - point densities (points per square meter) of the sea bed points (with $5 \mathrm{~m}$ isobath).

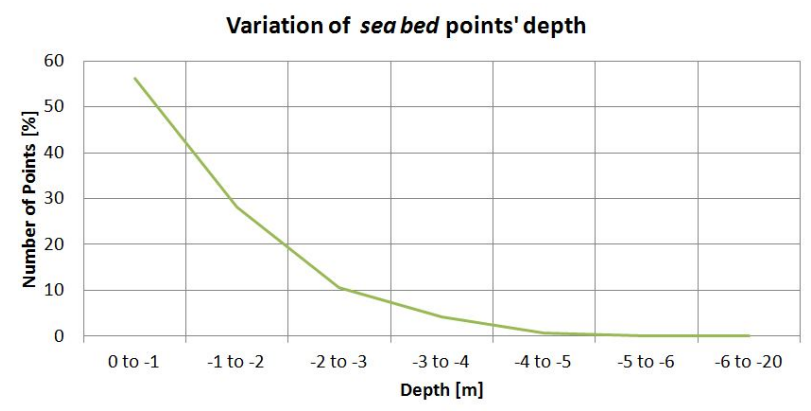

Figure 9: Number of sea bed points per depth level (Area 4).

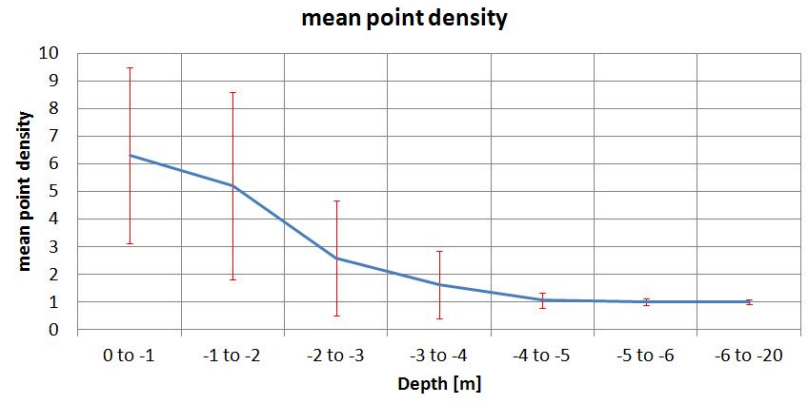

Figure 10: Mean point density of sea bed points per depth level (Area 4).

campaign will lie on the record of both, shallow water areas and deeper water up to 1.5 times of Secchi depth. Therefore it is planned to use a Chiroptera sensor for high resolution shallow water data acquisition, and a more powerful HawkEye II for the deeper areas. The latter sensor has an approximated range of up to 3 times Secchi depth. The survey is planned for the last week in September, 2013. Again the two Areas 1 and 3 close to Poel as well as two artificial reefs not far away from Rostock, Germany should be observed.

\subsection{Other finding}

One notable effect are gaps in the point clouds close to the coast of Poel in both data sets. The HawkEye II used in the pilot study as well as the Riegl VQ-820-G from the first project campaign were not able to record data in nearly the same areas although it is quite shallow water with depth of approx. between $1 \mathrm{~m}$ and $2.5 \mathrm{~m}$. Such a situation is shown in Fig. 11.

The reason therefore might be a certain sea bed sediment having bad reflectivity characteristics, or for example some kind of sea grass or Algae absorbing the laser pulse energy. Further investigations on this issue will be carried out.

\section{CONCLUSIONS AND OUTLOOK}

This paper presents the project 'Investigation on the use of airborne laser bathymetry in hydrographic surveying' from the German Federal Maritime and Hydrographic Agency (BSH) in cooperation with the Institute of Photogrammetry and GeoInformation, Leibniz Universität Hannover, Germany. The goal is to determine the limitations of the laser bathymetry (ALB) technique and possibly figure out potentially suitable areas for which ALB is more economical than ship-borne echo sounding. In the three years an annual surveying flight is conducted. At the current state of the project we got the data obtained from the first campaign

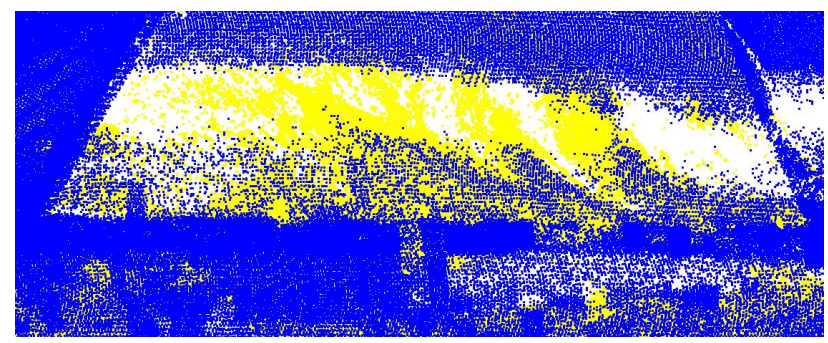

Figure 11: Gaps in data sets of HawkEye (blue) and Riegl (yellow). 
and briefly reviewed the point clouds. A Riegl VQ-820-G sensor was used, which is designed for shallow water areas with a range of up to one time Secchi depth. Corresponding depths are observed in the acquired data. As expected, the point densities are higher in the very shallow areas. It decreases notable in regions lower than $-4 \mathrm{~m}$. However, the distribution of the actual depth values of the underwater topography in the test area is not yet considered in this analysis.

In the next months a detailed evaluation of the results will be conducted. Beside the laser bathymetry also a data set of satellite bathymetry was bought in order to evaluate the potential of this technique in comparison to a surveying flight with laser. The accuracy and quality of the depth data delivered by a RapidEye 3 sensor will be analyzed.

\section{ACKNOWLEDGEMENTS}

The authors would like to thank Dr. Wilfried Ellmer, Annett Büttner and Wolfgang Sent from BSH Rostock for the data and many productive discussions.

\section{References}

Airborne Hydrography AB, 2013. Chiroptera - Technical Specification. http://www.airbornehydro.com/ chiroptera-technical-specification.

Costa, B., Battista, T. and Pittman, S., 2009. Comparative evaluation of airborne lidar and ship-based multibeam sonar bathymetry and intensity for mapping coral reef ecosystems. Remote Sensing of Environment 113(5), pp. 1082-1100.

Guenther, G. C., Cunningham, A. G., LaRocque, P. E. and Reid, D. J., 2000. Meeting the accuracy challenge in airborne lidar bathymetry. In: Proceedings of the 20th EARSeL Symposium: Workshop on LIDAR Remote Sensing of Land and Sea, Dresden, Germany, pp. 1-28.

Hickman, G. D. and Hogg, J. E., 1969. Application of an airborne pulsed laser for near shore bathymetric measurements. Remote Sensing of Environment 1(1), pp. 47-58.

International Hydrographic Organization, 2008. IHO Standards for Hydrographic Surveys. Special Publication N 44, 5th Edition. www.iho.int/iho_pubs/standard/S-44_5E.pdf.

Irish, J. L. and Lillycrop, W. J., 1999. Scanning laser mapping of the coastal zone: the shoals system. ISPRS Journal of Photogrammetry and Remote Sensing 54(2), pp. 123-129.

Lillycrop, W. J., Wozencraft, J. M. and Pope, R. W., 2002. Airborne LIDAR Hydrography: a Vision for Tomorrow. Sea Technology 43(6), pp. 27-34.

Mallet, C. and Bretar, F., 2009. Full-waveform topographic lidar: State-of-the-art. ISPRS Journal of Photogrammetry and Remote Sensing 64(1), pp. 1-16.

Riegl, 2013. Datasheet RIEGL VQ-820-G. Riegl Measurement Systems, http://www.riegl.com/uploads/ tx_pxpriegldownloads/10_DataSheet_VQ-820-G_ 10-06-2013.pdf.

Steinbacher, F., Pfennigbauer, M., Aufleger, M. and Ullrich, A., 2012. High resolution airborne shallow water mapping. In: International Archives of the Photogrammetry, Remote Sensing and Spatial Information Sciences, Proceedings of the XXII ISPRS Congress, Vol. XXXIX-B1, Melbourne, Australia, pp. 55-60. 